First Peoples Child \& Family Review

A Journal on Innovation and Best Practices in Aboriginal Child Welfare Administration,

\title{
First Nations Women Workers' Speak, Write and Research Back: Child Welfare and Decolonizing Stories
}

\section{Michelle Reid}

Volume 2, Number 1, 2005

URI: https://id.erudit.org/iderudit/1069536ar

DOI: https://doi.org/10.7202/1069536ar

See table of contents

\section{Publisher(s)}

First Nations Child and Family Caring Society of Canada

\section{ISSN}

1708-489X (print)

2293-6610 (digital)

Explore this journal

Cite this article

Reid, M. (2005). First Nations Women Workers' Speak, Write and Research Back: Child Welfare and Decolonizing Stories. First Peoples Child \& Family Review, 2(1), 21-40. https://doi.org/10.7202/1069536ar

\section{Article abstract}

This research is a similar study to Gold's (1998) study on the promotion of physical and mental health of mainstream female social workers in child welfare. Six First Nations women Child and Family Service (CFS) Social Workers (FNWCFSSW's) who work in First Nations agencies gathered with me to share individual and collective stories about our CFS experiences. First Nations women and I discussed the impacts of our work on our holistic health, how we coped with the work, and strategies to deal with the issues that we face. This study outlines the research process that we engaged in, and, essentially weaves together the challenges, resilience, innovations, and unique experiences of First Nations women CFS Social Workers in a First Nations setting under a delegated authority model. As a result of these discussions five major themes were identified. The five themes that emerged from this study include the stress of dual accountability, the stresses of unrealistic expectations and multiple roles, the emotional costs and benefits of the intensity of the relationships, the fact that meaningful work gives strength and how the women coped and maintained their holistic health. This study reveals the important need for future participatory research to be conducted with FNWCFSSW and First Nations peoples. Ultimately, this paper speaks to the importance of changing the nature of along-term colonial relationship between Aboriginal and non-Aboriginal peoples within the child welfare system and in dominant mainstream research processes.
This document is protected by copyright law. Use of the services of Érudit (including reproduction) is subject to its terms and conditions, which can be viewed online.

https://apropos.erudit.org/en/users/policy-on-use/ 


\section{First Nations Women \\ Workers' Speak, Write and \\ Research Back: Child Welfare \\ and Decolonizing Stories}

\section{Michelle Reid}

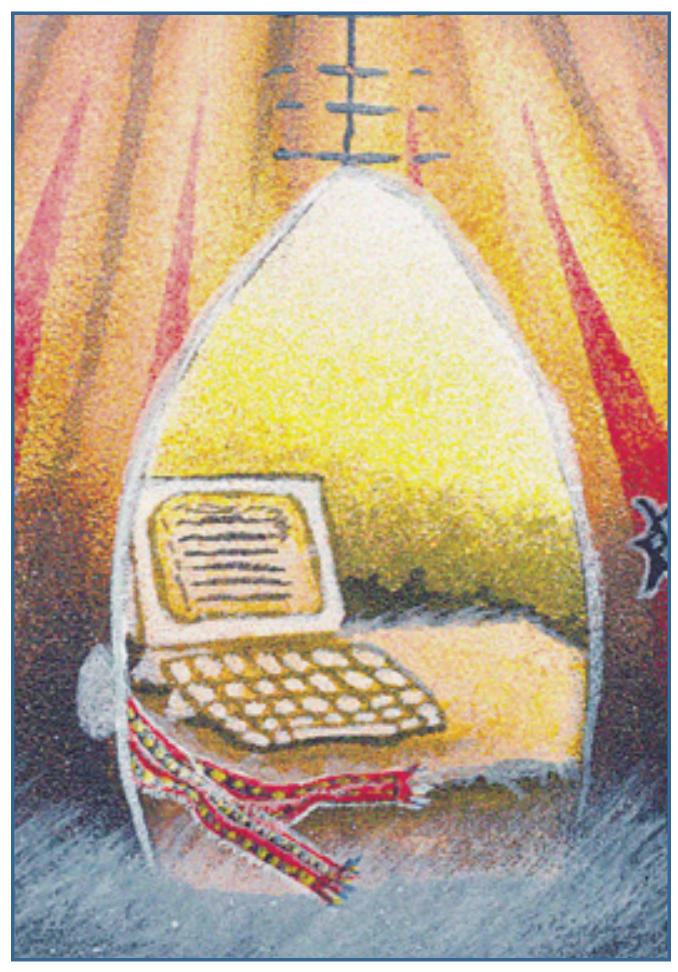

Abstract

This research is a similar study to Gold's (1998) study on the promotion of physical and mental health of mainstream female social workers in child welfare. Six First Nations women Child and Family Service (CFS) Social Workers (FNWCFSSW's) who work in First Nations agencies gathered with me to share individual and collective stories about our CFS experiences. First Nations women and I discussed the impacts of our work on our holistic health, how we coped with the work, and strategies to deal with the issues that we face. This study outlines the research process that we engaged in, and, essentially weaves together the challenges, resilience, innovations, and unique experiences of First Nations women CFS Social Workers in a First Nations setting under a delegated authority model. As a result of these discussions five major themes were identified. The five themes that emerged from this study include the stress of dual accountability, the stresses of unrealistic expectations and multiple roles, the emotional costs and benefits of the intensity of the relationships, the fact that meaningful work gives strength and how the women coped and maintained their holistic health. This study reveals the important need for future participatory research to be conducted with FNWCFSSW and First Nations peoples. Ultimately, this paper speaks to the importance of changing the nature of a long-term colonial relationship between Aboriginal and non-Aboriginal peoples within the child welfare system and in dominant mainstream research processes. 


\section{Introduction}

We don't want our children to be dealing with the stuff we are dealing with as First Nations people now. I don't want my child or any other First Nations child to be sitting at the negotiation tables and fighting for their inherent rights. My children and our children are my strongest motivator for being in this [CFS] work.

(First Nations Woman Child and Family Service Social Worker participant).

This quote captures the heart, spirit and underlying commitment and purpose that all of the women spoke of for engaging in CFS work and importance of becoming involved in this research. It is predominantly women who work as the social workers within the approximately 120 First Nations CFS (on-reserve) agencies across Canada, which is why this study focuses primarily on FNWCFSSW. The effects of the Indian Act and the past provincial CFS laws, policies and actions within Canada on First Nations peoples' holistic health are widely documented, but there seems to be little published about the impacts of the work on the CFS worker's themselves.

Research to date has explored the impact of non-First Nations female child protection social workers' work on their health and reported that the work does negatively impact their health. Numerous studies have utilized a feminist approach but there has not been a study conducted from a First Nations gendered analysis or approach. Although there may be similar challenges between mainstream female CFS social workers and First Nations women social workers regarding the impacts of their work on their health, this research specifically explores the impacts of the work on the holistic health of women social workers who work within reserve-based First Nations child and family service (CFS) agencies.

This research is an attempt to be the beginning of a continuing conversation that brings forward a greater understanding about the unique differences in terms of the setting, context, cultures, and experiences of the women that impacts their holistic health. This research is both an assertion of First Nation's women's voices and a reaching out to the minds and hearts of all, especially those involved in CFS and social service organizations to change the nature of a colonial relationship with Aboriginal peoples and embrace social justice. Within the child welfare arena the struggle continues to be for the right to be ourselves as distinct cultural peoples who have inherent rights to have our traditional lands, identities, cultural ways and practices respected and protected.

\section{Research Purpose:} Honouring Space, Validating Voices and Reaching to the Minds and Hearts of Many for Change

The purpose of this research is to honour and provide space for the women to give voice and engage in a research process that is respectful, meaningful, relevant and beneficial to them and other First Nations peoples, specifically other First Nations women CFS Social Workers. This research validates women's experiences and provides insight into the effects of their work on their holistic health. This study promotes the holistic health and self-care for women and is a beginning process for women to develop individual and collective strategies to better ensure and rebalance their holistic health.

The research process attempts to build a bridge between a mainstream school of social work research course and a First Nations' way of doing research. Hopefully, this research will raise the consciousness and challenge the assumptions of the Canadian federal and provincial government systems and employees, schools of social work and social workers (students and field workers), and researchers who work or will be working with First Nations CFS agencies, communities and peoples.

Specifically, this paper encourages critical analysis by these groups and individuals on how their CFS laws, systems, policies and actions may be harmful towards First Nations peoples, including FNWCFSSW, or may be part of the process of reconciliation and decolonization between Aboriginal 
and non-Aboriginal peoples. The following section provides an overview of my story and how the research began.

\section{Researcher Standpoint: The Beginning of the Research Process}

This research project is rooted in my own personal and work experiences as a Heiltsuk woman. My personal struggle continues to be to maintain and reclaim my Heiltsuk identity amidst the colonial policies, structures and barriers that exist. My commitment is to protect the cultural identities of the current and future generations of First Nations peoples and advocate for our self-determination.

My work experiences have taken me through the dominant mainstream education and other social service systems. I have felt the effects of my work experience in the CFS field and witnessed the colonizing effects on the holistic health of my female colleagues. I had been working for five years in my home community planning, organizing, and delivering the services of a CFS agency. I have experienced the struggles of working under a delegated system and building relationships with federal and provincial representatives. I have also felt fierce pride and identified many issues in working with First Nations peoples. After working tirelessly to assist in the emergence of a community based CFS Agency, I decided to take a year's leave from my position. I wanted to pursue my MSW, reflect on own experience with the CFS work and attempt to rebalance my health which had been impacted by the strain and intensity of doing the work.

As I reflected on my many interactions and experiences with First Nations women who were working in similar capacities, I began to recognize that many of my colleagues' health were also being affected by the work. Since I was in a university graduate program and had an opportunity to conduct research, I wanted to generate honest dialogue with First Nations CFS Social Workers to see how their work impacts their holistic health. I was committed to doing research in a manner that was going to be relevant to both First Nations peoples and myself, despite the challenges that I faced in the mainstream academic program and research course. I was determined to no longer leave myself at the door as a Heiltsuk woman. I wanted to ensure that, along with the First Nations knowledge, experiences, research relationships and processes, my own tacit knowledge was validated most meaningful for First Nations peoples. During my literature review, I located a study by Gold (1998) that was similar to what I wanted to explore in my research with the women. The next section provides an overview of the research I conducted which was similar in concept to that conducted by Gold.

\section{Previous Research: A Similar Study}

Gold (1998) used a feminist critique and approach to interview 40 female Child Protection Social Workers about the impact of their work on their mental and physical health and how they coped and protected their health. She found that "despite some of the rewards associated with child welfare work that the women experienced their work as damaging to their mental and physical health"(p.717). This current study addresses the issues that Gold's study did not by interviewing FNWCFSSWs who not only experience patriarchy, but also experience colonialism and racism that is perpetuated through the current CFS laws, policies and practices. Furthermore, I endeavored to use a participatory community action research approach that emphasized the community context that the women identified as being important to them as part of their First Nations gendered analysis.

Gold's (1998) study explored the physical and mental impact of the work on female child protection social workers' health, whereas this study explored the holistic health of FNWCFSSW as defined by the participants in this study. Another difference is that the participants in Gold's study worked in mainstream Ontario Children's 
Aide Societies, while the FNWCFSSW worked in reserve based delegated First Nations CFS agencies. Furthermore, Gold's study emphasized an individual focus, whereas this study emphasizes a First Nations family, community and cultural context. Timpson (1995) notes that "Native agencies face the challenge of working with just not individual problems, but problems that affect the entire communities and require community healing and the prevention of further intergenerational damage" (p. 540). This challenge could impact the holistic health of FNWCFSSW because it is difficult to meet the needs of an entire community.

Given the similarities and differences and an interest from the FNWCFSSW in the field, this study was initiated (1) to explore the impacts of CFS work on FNWCFSSWs' holistic health and (2) to identify how FNWCFSSWs' coped and what strategies they used to rebalance their holistic health. The theoretical perspective of the gendered First Nations perspective and decolonization approach used for this research is discussed in more detail in the following section.

\section{Theoretical Perspective:}

\section{A Gendered First Nations Decolonization Approach}

Smith notes that "research" is one of the dirtiest words in the Indigenous world's vocabulary... (and) has been linked inextricably with European colonialism..., scientific research and placed indigenous peoples as the other" (1999, p. 1). Therefore, I endeavored to engage in a participatory community action research approach, and rely on participants' gendered First Nations analysis that emphasized the community, cultural and family context that the participants all identified as being important.

A gendered First Nations perspective is specifically through the eyes of First Nations women". Feminism in the context of a First Nations analysis is distinguishable from a mainstream feminist ideology; it incorporates not only an analysis of patriarchy, but includes an analysis of the impact of colonization and state oppression (Sayers \& MacDonald, 2001, p.8).

Overall, a gendered First Nations perspective helps ensure that the research process does not become an act of colonizing or disrespecting the women who courageously participate, but is a means of decolonization in which we can "research back", "write back" and "talk back" (Smith, 1999, p. 7).

$$
\begin{aligned}
& \text { Decolonization does not mean and } \\
& \text { has not meant a total rejection of } \\
& \text { all theory or research or Western } \\
& \text { knowledge. Rather, it is about } \\
& \text { centering our concerns and world } \\
& \text { views and then coming to know and } \\
& \text { understand theory and research from } \\
& \text { our own perspectives and for our } \\
& \text { own purposes (Smith, 1999, p. 39). }
\end{aligned}
$$

Like Gold's (1998) Study, this current research explores women child and family service child social workers' experiences and the impacts of their work on their health. There is a large body of feminist literature that critiques the child welfare ideologies, laws, policies and practices and explores the "gendered nature" of the work and the impacts and stress on female child protection social workers (Gold, 1998; Swift, 1995; and Callahan 1993). While Gold (1998) explored the gendered nature of the work, she did not include a gendered First Nations analysis or perspective, specifically.

There is an increasing body of literature from First Nations women's perspectives that analyze the impact of patriarchy, colonialism, and the imposition of social (CFS) services and health systems and practices on First Nations people's health; however, there does not appear to be literature that examines explicitly the impact of the CFS work on FNWCFSSWS' holistic health (Gunn Allen, 1992; MontureAngus, 1995; Maracle, 1996; Huntley \& Blaney, 1999; Sayers \& MacDonald, 2000; Anderson, 2000; Stewart, Huntley \& Blaney, 2001; MacDonald, 2002; Ouellette, 2002; Anderson \& Lawrence, 2003; 
Lawrence, 2004; and Mihesuah, 2003;).

The First Nations CFS literature outlines that the CFS social work laws, policies, practices and ideologies have been and continue to be premised on Eurocentric, colonial and paternalistic relationships, values and beliefs and outline the ongoing aspirations of First Nations peoples towards self-government and self-determination. In addition, the literature critiques the Province of British Columbia's Delegation Enabling Agreement (DEA) (Mckenzie \& Hudson, 1981; Johnson, 1983; K.L. Lee and Associates, 1992; Kline, 1992; Wotherspoon \& Satezwich, 1993; Armitage, 1993; Absolon, Mitchell \& Armitage, 1996; MacDonald, 2000; Brown, Haddock \& Kovach, 2001; and Blackstock 2001). This literature does not focus on "a gendered First Nations analysis" or the impacts of CFS work on FNWCFSSWs' holistic health.

There is an emerging body of literature that outlines Aboriginal research perspectives and decolonizing approaches (Kirby, 1989; Hampton, 1995; Gilchrist, 1997; Mihesuah, 1998; Smith, 1999; Martin, 2001; Blackstock \& Bennett, 2002; Sinclair, 2004; Absolon, 2004; Brown \& Strega, 2004; Absolon \& Willet, 2004; Kovach, 2004; and Thomas, 2004;). The next section provides a brief overview of the First Nations peoples' worldviews as it relates to traditional child rearing practices, along with the past and current child and family services laws and delegated enabling agreements to provide a conceptual framework of the unique context and setting that the First Nations women live and work with that could impact their holistic health.

\section{A Conceptual Framework: Setting The Research Context \\ Thousands of Years of Caring for Our Children: Traditional First Nations Child and Family Systems}

For thousands of years prior to colonization First Nations peoples had strong and thriving cultures, worldviews and diverse tribal, social, political, economic, spiritual and support systems that ensured the holistic health and well-being of our children. Blackstock (2003) states, "the holistic worldview held that in order for a child, family or environment to achieve an optimal level of functioning, the physical, emotional, spiritual and cognitive must be in balance" (p.333). When issues arose within families regarding the care or well-being of children, the communities would deal with the issues within a community context that was rooted in relationships and systems of accountability. The holistic worldview, interdependence and cultural ways of knowing and being shaped all facets of First Nations peoples' lives, including concepts and practices of maintaining their individual and collective holistic health as First Nations peoples.

\section{Residential School and Child Welfare: Historical Overview}

The Canadian government's colonial policies attacked all levels of First Nations societies. Their cultural systems and practices were criminalized and demoralized under the Indian Act and other colonial mechanisms, including the child welfare system. The imposition of Canadian child and family service laws and systems on the lives of First Nations peoples started in the 1890's with the implementation of the Indian Act and the policy of mandatory attendance to residential schools, and was later reinforced with the 1951 extension of the child welfare system onto reserves. Both the multigenerational effects of residential school and the child welfare system on the lives of Aboriginal children, families, communities and cultures have been well documented and continue to be evidenced by the social, health, justice factors that surface within First Nations communities today. Furthermore, current child welfare and social work practices are viewed by many as continuing the cultural genocide, patriarchy and racism that impact the lives of First Nations women and children (Johnson 1983; Howse \& Stalwick 1990, 1993; Hamilton \& Sinclair, 1991; Kline 1992; Timpson 1995; Absolon, Mitchell \& Armitage, 1996; RCAP 1996; MacDonald 2002; and Blackstock 2004). 


\section{Current Day Child Welfare \& Delegation Enabling Agreements: Realities/Relationships}

The dominant mainstream Canadian society, social work profession and child welfare systems have acknowledged the impact of the residential schools and early child welfare laws, policies and practices on First Nations peoples. The Canadian provincial child welfare systems and bureaucrats have made commitments to engage in a new relationship with First Nations peoples, to reduce the number of First Nations children in care and to assist in improving the overall social and health conditions for First Nations peoples; however, there is little evidence that these proclamations have resulted in meaningful improvements for First Nations peoples.

Despite the realities and overwhelming socio-economic conditions of First Nations peoples and the numbers of First Nations children in care, Canadians continue to believe colonization is a thing of the past. They are not aware that First Nations peoples continue to be defined and bureaucratically controlled under the current colonial laws, policies and realities of the Indian Act and child welfare statutes.

Canadian government laws, policies and dominant practices continue to have a devastating impact on First Nations communities and cultures. First Nations peoples have proclaimed that, despite contemporary child welfare reforms, even more Aboriginal children are removed from their communities and end up being taken into state care and placed in NonAboriginal homes ("North Short of Help", 2001). Blackstock (2003) states, "First Nations children represent approximately $8 \%$ of the child population in Canada although approximately $35 \%$ of Canadian children in care are First Nations (p. 331).

\section{Delegation Enabling Agreements}

Since the 1990's one of the newest modalities of child welfare that First Nations in British Columbia operate under is the
Delegation Enabling Agreement (DEA). The DEA speaks to the level of authority delegated to agency social workers pursuant to the respective provincial legislation in British Columbia. The provincial government enables individual First Nations CFS agency social workers with specified powers to carry out support, guardianship and protection duties and functions under the provincial CFS legislation. This legislation, and therefore, the DEA, embodies Eurowestern based standards and practices

The federal Directive 20-1 provides the formula to fund on-reserve agencies for the provision of provincially delegated services. Directive 20-1 is a national funding formula administered by the Department of Indian and Northern Development (DIAND), which restricts funding to "eligible children on reserve." A population threshold (based on children 0-18 years of age) influences how much funding each First Nations CFS Agency receives. According to the policies of Directive 20-1, in most provincial jurisdictions, First Nations CFS Agencies must be incorporated under the provincial child welfare legislation which requires them to comply with provincial legislation and standards (Bennett, 2004). This arrangement effectively negates opportunities to affirm self-governing models.

The DEA is a complicated process because of the jurisdictional disputes and lack of coordination between the federal and provincial governments, which has resulted in First Nations children and communities being faced with huge inequitable gaps in funding and services (MacDonald, 2000; and Durst, Macdonald \& Rich, 1995). Within the context of such agreements, a scenario can arise in which the 'feds' hold the purse strings, the province holds the legal hammer, and the band is left to do the dirty and impossible task of addressing major social problems with insufficient human and fiscal resources (Durst, 1996, p. 16).

First Nations communities and peoples generally enter into CFS DEAs in order to access resources and authority to set up agencies to assist in dealing with the severe socio-economic issues facing their families, 
and to confront the staggering increase of First Nations children being removed from their communities and cultures. First Nations peoples have continued to actively protest the removal of so many of their children and advocate for the recognition and incorporation of their own cultural and community systems as being the best way of caring for their First Nations children. "The delegation model is founded on the [paternalistic and racist] notion of "giving" [provincial] authority to deliver child welfare services, rather than recognizing First Nations' inherent authority to care for their children" (Brown, Haddock \& Kovach, 2001, p.146).

Although many First Nations agencies believe that their work benefits their children, families and communities, they view delegation as an interim measure towards self-government. Overall, First Nations peoples remain vigilant about asking the Canadian government and society for relationships based on mutual respect, the sharing of power and accountability; relationships that the government and larger society has made commitments to.

The research methodology, including the recruitment criteria, participant overview, researcher relationship with the participants, data gathering, data analysis, and the one study limitation identified are the focus of discussion in the next section.

\section{Recruitment Procedures}

I used a purposeful sampling strategy to recruit the women in order to "achieve representativeness and answer the research question" (Maxwell, 1996, p. 70). The criteria included women who identified themselves as being First Nations and who have had two years of frontline child and family service experience in a First Nations CFS agency. I chose not to broaden the scope to offreserve or Aboriginal urban CFS agencies because I wanted to explore the specific First Nations Agency Social Workers' experiences. A letter of invitation to participate in the study was sent out to First Nations Child and Family Service agencies through the Caring for First Nations Children's Society in British Columbia.

\section{The Women Who Participated and Our Process}

The first six women from diverse First Nations cultural groups and agency settings contacted me directly and were selected on the basis that they would be in the Vancouver or Vancouver Island area during January or February of 2002 and would be able to arrange an interview. Three of the participants live and work within their own communities and three do not. The women's ages range between 30 and 50 years. Participants were women who identified themselves as First Nations social workers who have had two years of frontline child and family service experiences in an on-reserve CFS Agency. The women have worked between five and 25 years in the CFS area. Two of the women have also worked as provincial child protection social workers. The women share similar experiences of being directly or indirectly impacted by residential school and the child welfare system and see the impacts of colonization on their communities.

\section{Researcher Relationship with the Women}

Smith (1999) states that "insider researchers have to be ethical, respectful, as reflexive and critical... [and]... humble because the researcher belongs to the community as a member with a different set of roles and relationships, status and position" (p. 139). Participants said this research process and my relationship with them and with each other were important because I am an "insider researcher." My role as an "insider researcher" is derived from my identity as a Heiltsuk First Nations woman social worker engaged in providing Child and Family Services and I am also a part of the women's community. Given that I have known the women previously and shared a similar lived experience as a First Nations woman social worker helped to reinforce the trust and respect between 
us and provided the basis for the stories to be shared in the way that they were. I endeavoured to be respectful with the women by having open and honest conversations with them about the research topic, process and my responsibility as both a First Nations woman and a researcher. Smith further asserts that "Insiders have to live with the consequences of their processes on a day-to-day basis, as so do their families and communities (Smith, 1999, p. 137).

I felt a high degree of responsibility and accountability to the women, particularly to ensure that I respectfully and accurately captured their experiences in the research process and findings. In order to test my own taken-for-granted views about my lived and shared experiences as a FNWCFSSW, I communicated regularly to ensure that there was a feedback process from the women in order to capture their meanings.

\section{Making Meaning of the Stories: The Data Gathering and Analysis Process}

Qualitative methods are an essential component of research in First Nations communities in attempting to capture experiential knowledge shaped by both historical relations and a particular community context (Mckenzie, Seidl \& Bone, 1995 p. 638).

Individual interviews with open-ended questions were used for five of the six women. In person interviews lasted approximately two to three hours. Although I used an interview guide, the women guided the interview as to what was important for them to share about their experiences. I conducted one email interview using the same format as the other interviews. The women and I carried out our interviews where they were most comfortable and their privacy could be ensured, such as my home, or in their home. The women provided their informed consent and participated voluntarily. To maintain the confidentiality of the participants, whose communities are very small, identifying information was omitted from this study.

\section{Data Analysis}

Grounded theory was selected as the method for data analysis because it is seen as a "process, whereby theory is an ever-developing entity and not a perfected product" (Glaser \& Strauss, 1967, p. 87). "Grounded theory [also] supports the feminist [gendered First Nations analysis] epistemological underpinnings that participants are the experts about their experience and that subjective experience is valid knowledge (Wuest, 1995, p. 2).

I used grounded theory methodology to explore, analyze and extend knowledge about the participants' experiences of their work on their holistic health. Themes and findings have been conceptualized from transcribing the interview transcripts verbatim, analyzing the women's stories, and engaging in a systematic process of identifying relationships between the categories. Finally, conducting membership checks with the women ensured the themes were meaningful to them and the validity of the research. This process provided a foundation to the development of a theory that reflects the main connections of the impacts of the womens' work on their holistic health.

Four women and I gathered for dinner, and they gave me feedback about the initial research findings. The women discussed the importance of this research and the follow up meeting because it gave them the space to share, support and validate both their individual and collective experiences. To honour the women for the sharing of their stories and the work that they do with our children, families and communities, I offered them food and gifts (self-care gifts, feathers etc.).

\section{Research Limitation}

The sole limitation identified in doing this research is the small sample size of women who participated in this study. It is recognized that the sample does not make the findings generalizable to a larger population, although other FNWCFSSW could possibly have 
similar experiences and challenges of working and living in the same setting.

The women share and describe in the following research findings and results section the multi-dimensional impacts of their CFS work on their holistic health and how they have coped and what strategies they have used to rebalance their holistic health within the context of their own voices, experiences and political representation.

\section{Findings And Results}

\section{Presentation and Analysis of Findings}

The research findings provide rich information and insight into the experiences of the women who participated in this study. The women articulated that this research gave them the opportunity to "reflect", "think about" and "discuss" this important issue. One participant stated "this is the first opportunity that I have had someone ask me my experience as a First Nation women working in a First Nations community as a social worker."

During this research process, the women discussed life as being an experience of struggling constantly to get their "ways (CFS) validated within their own right and not within the paradigm of the western mainstream cultures." The women declared that "it is a myth that colonization is over," that they continue to remain in a "colonial", "racist" and "paternalistic" relationship with the Canadian government and CFS laws, policies, practices and systems which impact their holistic health.

The women acknowledged that some of the CFS work may impact their holistic health in ways similar to Non-First Nations female CFS social workers. They stressed that their experiences are unique because they work in different community and cultural settings that may involve the added complexity of working with their own families or extended family members or people that they have relationships with. Furthermore, the historical and current colonial relationship and context that they live and work in as First Nations women
Child and Family Service Social Workers presents unique and different challenges for them which impacts their holistic health.

The women believe that it is important to provide their definition of holistic health because they believe that their work does not simply impact their mental and physical health. The women describe holistic health as:

$$
\begin{aligned}
& \text { Keeping and incorporating all of the } \\
& \text { elements of yourself and your life: the } \\
& \text { physical, mental, emotional and spiritual } \\
& \text { parts of yourself are cared for and } \\
& \text { nurtured, and if you do that you will be } \\
& \text { okay, and you will be able to maintain } \\
& \text { balance and good holistic health. } \\
& \text { Not only trying to achieve balance } \\
& \text { in your life, but recognize what your } \\
& \text { needs are and have needs met. All } \\
& \text { of the aspects of your being are so } \\
& \text { intertwined and impacted by the work. }
\end{aligned}
$$

The women did not want to polarize completely the positive and negative aspects of their work on their holistic health. They wanted to conceptualize the realities, challenges and rewards that they live and work in as FNWCFSSW and how their work impacts their holistic health.

The major themes that were identified include: 1) stress of dual accountability; 2) the theme of meaningful work gives strength; 3) the stresses of unrealistic expectations as First Nations women and CFS social workers; and 4) the emotional costs and benefits of the intensity of relationships. Furthermore, how the women coped and what strategies they used to rebalance their holistic health were briefly examined.

\section{The Stress of Delegated Authority and Dual Accountability}

In terms of operating under the Province of British Columbia's CFS DEA and having dual accountability between the provincial and federal government and the First Nations community members that they work with, the women emphasized that their 
"duties and responsibilities are much broader and intense", as well as "very large and complex", "unrealistic" "contradictory" and "unmanageable." The women believed that the colonial relationship and delegated model that exists between them and the Canadian government creates "the greatest source of their frustration", "tremendous pressure from all sides", "lack of power and control" and "stress." Although the women stated that there are some good relationships with individual DIAND or MCFD (Ministry of Child and Family Department) employees, overall the relationship is described as "not easy", difficult, "about power and control" and "crappy". In addition, this relationship creates the most "challenges" and directly impacts their holistic health.

The women discussed the "pressure" and "pain" of working under the delegated models within their communities where they are dealing with the ongoing "impacts of colonization" and do not want to be seen as "perpetrators of colonialism" towards their own people. One participant stated that "we do not want to duplicate the past CFS failures towards First Nations people." Another participant stated "the delegated relationship is disempowering because we are forced to work under an imposed foreign systems which often creates cultural conflicts." Another participant stated their belief that "this provincial system, process and language that is being imposed on us does not support and promote us as First Nations women to work in this field and stay healthy." The women believed that it is a daily challenge in their work to attempt to "walk between two worlds", "get their own worldviews", and have their "cultural child care practices" validated and incorporated into their programs. Another participant described the delegated situation as "working between conflicting cultures and not having any shared power or control."

Furthermore, the women felt that the delegated and colonial relationship was "tiring", "draining", and "taxing" on the "heart", "body", "mind" and "spirit". One participant stated that "when we signed our DEA, I had to take time off because of the stress." The women believed it is "hard", "difficult" and "draining" to live with the "ethical muteness" of the government towards the "plight of First Nations people." The women expressed their "burden" of "explaining" and "justifying" their realities while "advocating" for government changes and funding that will benefit First Nations children and families.

The women spoke about the "huge pressures", "inequitable and insufficient resources", and the "lack of infrastructure and capacity" from the government to do their work. The women felt that the insufficient funding and capacity within their agencies and communities contributed to the multiple roles that they ended up taking on. One participant said, "I am the Director. I also have to double as a Supervisor when we are short staffed and I do most of the investigations. I also do the community and political work with the regional, federal and provincial government and I sit on various committees and boards." Another participant stated, "a lot is asked of you...you work long hours, and it is difficult to feel you have done a job well enough and met all of the responsibilities and demands. The women emphasized that the "strain" of their work can "make you sick", "suck the life right out of you" and "almost kill you."

\section{Meaningful Work Gives Strength}

The women discussed the meaningful work that gives the strength and includes (1) dealing with the historical injustice and intergenerational impacts of colonization, (2) is a motivating force, (3) benefits the children and families that they work with, (4) and provides creativity, inspiration and meaning in their lives. The women in this study found many positive aspects of their work that gave them strength. The women found the work gave them "meaning in life" and "inspiration" and was "the greatest source of strength" and "a motivating force" when the work that they are doing is "benefiting children and communities." The women believed strongly that the work could be "creative" and "innovative." One participant shared that "these innovations that are based 
on thousands of years of successful caring for children, families and communities and the challenge is to find and think of ways to bridge it forward." The women identified that the reason why they do this work is because of their love for the communities that they work with and want to contribute towards and see "positive" and "meaningful" changes and "freedom" for their children, families and community, both for the present and future generations. One participant stated:

\section{To be working with members of your own community and to be feeling that level of responsibility, commitment and passion towards the work is so much higher. It is much more difficult when you feel that you are not able to meet all of the needs and you aren't able to make some of the changes that you want to make.}

The women all stated that their work is more than a job and not just about a pay cheque. One participant stated,"This work is more than a job or a pay cheque; it is about my community and grandchildren's future." The women agreed that because they are working with "historical injustice", "intergenerational impacts of colonization" and "people that they know and care about" that the level of duty and responsibility is much higher and can be "all-consuming" and "trying", leaving little time to keep themselves well. Furthermore, one participant said, "We are living and going home everyday and see the results of our work around us." They also spoke of the challenges and benefits of bringing their own experiences of colonization to the work. They felt that having a similar experience of colonization with the people that they work with makes them "strong social workers" and also requires a need for them to be "self-aware" and "healthy" and to "support" one another so that they do not become "ineffective" in their work.

I think what mostly makes me happiest about my work is seeing the kids. We go out to the communities... You watch the foster kids who bave come back home and are with their families... When you watch kids interacting in a positive way with their families and you just know that this work is contributing and that everything is going to be fine.

\section{The Stress of Unrealistic Expectations and Multiple Roles}

The women discussed the unrealistic expectations that come with (1) the lack of boundaries and expectations that the community members bave towards them; (2) being women and their work impacting their children; and (3) the risks involved in the work.

The women suggested that the lack of boundaries and expectations that the community members have towards them and their work can elevate their stress. In the small rural communities, "You are the service... and expected to be available 24 hours a day, or so it seems." One participant said, "You cannot live and breathe this child protection work 24 hours a day and it not have a huge impact on you on all levels."

The women suggested that the work that they do is "community development work" and their caseloads are based on families, not individuals, which can make the work both more "fulfilling" and "challenging." The women believed that their role can be "difficult" and "contradictory" because they are attempting to "support", "empower", "provide culturally relevant services" and ensure "the safety of and well-being of children in a child protection role" in a system that is about being "directive and asserting authority", which is a difficult balance. One participant stated, "this (mainstream) social work system is set up to create imbalances and total unhealthiness, and, somehow, we are still expected to work towards restoring balance and health to people...it just doesn't work that way." Three women stated that they have to be "thoughtful" and "hyper-vigilant" in their decision-making because they are aware that their decisions impact children and families' lives forever. One participant said, "Sometimes I feel fear in making some decisions and it has made me sick."

The women suggested that women generally have more unrealistic demands placed on 
them because of the responsibilities with their family, community, cultural and social work roles which increased their stress and impacts on their holistic health. The women believed that women "value" and "engage" in relationships more and make "emotional connections" which is why many of them are social workers. They felt that, as social workers, they are always dealing with the "extremities of emotions" and the "pain" of the people they work with. Three women believed that they are expected to maintain "emotional distance" in their work, without the supports and time to debrief which can be overwhelming. One participant expressed that "a lot of energy goes into not feeling in this work." Another participant summarized:

\section{As a First Nations woman you try to do it all. As a mother and a wife, you have to be perfect at doing everything in your work, your family and your community life. So, for many years, I didn't do for myself because I was too busy doing for everyone else and I ended up with severe stress and sickness and only then having to begin to finally take care of myself.}

The women who are mothers felt a lot of "guilt" and "worry" about their families suffering because of the time and energy they spend working. Two of the women worried about their children being "teased" or "negatively impacted by other kids" because of the decisions that they make in their work. The women also expressed their concerns as women about the lack of attention paid to the elements of "risk", "danger", "threats", and "fear" in doing child protection work. One participant said, "When you are dealing with dangerous situations in homes...there is that expectation as a social worker that you will always be strong, but there is always that vulnerability which can be 'terrifying'." Another participant discussed getting numerous "hang up" calls right after a removal was completed.

\section{Emotional Costs and Benefits of the Intensity of Relationships}

The women felt that knowing their clients could be a "strength" or "cause potential (C) Michelle Reid conflicts" in their work. Strengths can engage in building "sustainable", "trusting", "honest" and "established" relationships with people to create meaningful changes. The three women who do not work within their own First Nations communities or with their own families believed that working within your own community is much more challenging and involves more pressure and stress because the work is "up close and personal" and "can't be objectified as being out there because it is right here." One participant stated that, "We aren't strangers working with strangers so there is that complete accountability all the time." Another participant stated that "We are seen as community members first and social workers second, so the impacts on our health is higher." The women articulated some of the challenges of working with their own family and community members such as dealing with difficult and uncomfortable interactions with family members, the credibility of their work being challenged and the issue of maintaining confidentiality when the work is right in their own backyard.

The women further felt that there is a different level of "love", "passion", "engagement", "connection", "commitment", "loyalty" and "accountability" that comes with working in a small community. The three women who worked or are working within communities that they are not from believe that the community members want to know who you are, your history and where you and your family come from and your values and beliefs and that these can create trusting relationships.

The women emphasized that it is "energizing", "grounding" and "wonderful" to have opportunities such as community dinners to be able to "celebrate" the strengths of the children, families, community and culture. They articulated that the work could also be very "rewarding" and "gratifying" when they see children and families prospering in the community and they know their work is making a contribution. They also felt it could be "emotionally draining" when things don't work out for the children and families because you want to see them "empowered", "happy", "safe", "healthy" 
and "successful within their own right" and "it is hard when you see children and families in pain." One participant stated, "the community can be supportive and invite you to cultural gatherings or confront you in the local store or mall." Another participant said that "when people are angry in the community about a decision that I made, the s---t hits the fan and I have to avoid going to certain social functions." The women stated that even though the work can create a lot of conflict with the people and they sometimes felt "devalued" or felt a "lack of recognition" in their work, there are always going to be people who are "thankful for your presence in their lives." In addition, the women felt that they do not get enough personal time living and working in a small community setting. The women sometimes felt "stress", "exhaustion", "frustration", or "isolation" or "alienation" when they were "approached in public places", "receive after-hours calls" or are "ostracized" for the work that they do:

you are under a microscope... and your parenting and social life is in the limelight... in this work and you don't have the luxury of the type of privacy that people in cities have and it becomes increasingly stressful because everything can challenge your credibility.

The women all believed that giving all the time is hard on their well-being and that there needs to be personal time and boundaries around work in order to rebalance and truly be there for the children and families with whom they work.

\section{Coping and Holistic Health}

The women suggested that the stress, unrealistic demands and pressures from both themselves and all of the people involved in their work and lives contribute to some of the "chronic health issues" that they experience such as "headaches", "backaches", "stomach aches" and "canker sores." In addition, the women reported that some of the ways that they cope are through "a lack of sleep", "not eating properly", "a lack of exercise", and "extreme weight gain or loss". One participant said, "I have made the connection for me between smoking... eating lots of sugar and addiction and stress."
Another participant declared, "In this work it is easy to disconnect with your body and be out of tune because of the stress." The women felt that their "immune systems" and "physical resistance" are compromised by the stress of their work which can lead to "low energy" and "serious illnesses."

The women also felt that their work contributes to feelings of being "tired", "mentally stressed", "fatigued", "too old for age", "sad", "angry", "depressed", "guilty", experiencing "low self-esteem", "hopelessness" "bitterness" and were "worried" and in "denial" about their health. The women discussed the implications of this stress as resulting in them taking stress leave, having to change jobs, finding it difficult to get out of bed some mornings and becoming forgetful about very important things. Four of the women also suggested that it is difficult with the lack of organizational supports to deal with the ongoing "vicarious trauma" associated with their work themselves.

Three of the women emphasized that in social work it is easy to take on all the responsibilities and "negativity" and "toxicity" of their work into their bodies and "normalize" the stress and sickness. One participant stated, "I don't think the accumulated stress of this work leaves my body and that is why I have the physical illness and sickness." A second participant stated, "You have to be all to everybody and you can't be sick...people will still call and they know where you live." A third participant said, "You are the be all and end all to fix problems and deal with all the emergencies in the communities."

Three of the women shared stories of near death experiences that were related to severe stress. One participant stated, "I thought I always tried to take care of myself and then I ended up in the hospital...I almost died. One participant said, "Sometimes, no one is there to help us or support us or pick us up until we crash."

Strategies for Restoring Holistic Health and Balance 
The women identified various strategies for restoring and rebalancing their holistic health which will be presented under the headings of 1) systemic, 2) individual and 3) collective strategies.

\section{1) Systemic Strategies}

One participant stated, "We need to have other ways of providing services to our own people rather than going through this process and provincial legislation." The women agreed that the agencies needed "equitable" and "sufficient funding." The women agreed that self-determination and self-governance would benefit their holistic health by being able to provide their own "culturally and community based services." The women also felt that receiving "equitable", "sufficient" and "adequate" resources would decrease the stress of them having to advocate with the government for resources. Many of the women believed that there needs to be "more women in leadership positions" to ensure that the community health and social issues are being addressed. Additionally, the women noted, "in terms of training, I don't think the mainstream school of social work trains or prepares us." One woman articulated, "It is important to get education in social work institutions that validate and honour our ways of knowing and being and also incorporate rural social work and community practice." Another participant stated,

$$
\begin{aligned}
& \text { Social work needs to be redefined so } \\
& \text { that it fits with a First Nations way } \\
& \text { of working with children and families } \\
& \text { within our communities and cultural } \\
& \text { contexts. Also, holistic health needs to be } \\
& \text { looked at and addressed in terms of the } \\
& \text { mental, emotional, physical and spiritual } \\
& \text { needs of First Nations social workers. }
\end{aligned}
$$

The women agreed that there needs to be "relevant", "adequate", and culturally appropriate training for the First Nations agency social workers. They spoke of the need to have a more "holistic", "interdisciplinary" and "integrated" approach to providing services to children and families in their communities. "Education" and "ongoing dialogue" was identified as being important by the women in order to engage people in a collective process to address (C) Michelle Reid underlying issues that impact First Nations peoples' holistic health and their own.

\section{2) Individual Strategies}

Some of the major individual strategies that the women identified included, the need to create "boundaries", "stop feeling guilty for time that you need for yourself", ensure "self-awareness", "meet and nurture all holistic aspects of self", "exercise", "eat properly", get "adequate sleep", "make space to process and debrief", "create supports inside and outside of community", seek out "mentors" and "peer supports", and ensure "spiritual practices and cleansing."

\section{3) Collective Strategies}

Some of the collective strategies that the women identified included, sitting down and talking with other social workers about, "what drains us and motivates us in this work", "the challenges and issues of maintaining holistic health" and "self-care and balance strategies for social workers." Furthermore, the women discussed the importance of ensuring there is "mentoring in agencies and communities" that "supports" their important work, ensuring and creating "boundaries around work", "dialogue on all levels", "community education and "involvement."

One participant declared,

We need to create boundaries between who we are and what we do and ensure that there is ongoing dialogue happening with the community, so that they are clear about everyone's role and responsibilities in caring for and ensuring the safety for our children.

\section{Discussion and Conclusion}

Although Gold's (1998) Study findings relate to the experiences of First Nations women CFS Social Workers, the FNWCFSSW participants in my study felt that her study did not capture their experiences of colonialism, or working in a community or different cultural context and its impacts on their holistic health. While Gold's (1998) study categorized 
results into positive and negative aspects of physical and mental health, the women in this study chose not compartmentalize their experiences into positive and negative aspects. The FNWCFSSW wanted to highlight the impacts of their holistic health which also includes the spiritual and cognitive aspects. Like the participants in Gold's study, the FNWCFSSW had similar feelings of powerlessness and lack of control that related to the stress, pressures, lack of resources, lack of personal and professional boundaries, as well as the patriarchal reality that the CFS system operates from.

Overall, the women believe that they are in a colonial relationship with the Canadian government and work between two different cultural systems. The difficult role of managing dual accountabilities makes the work "larger and more complex than that found in non-First Nations communities" (Brown, Haddock \& Kovach, 2001, p. 147). The work has huge impacts on their holistic health; resisting the dominant mainstream child welfare system and other colonial mechanisms while advocating for validation of their own systems creates stress and takes a great deal of personal and professional time and energy.

The women in this study not only experience powerlessness in their work, but also in their personal lives as First Nations women who are still under colonial laws, policies and practices. They also all understand intimately the impacts of colonization and want their work to benefit their communities in a positive way that does not cause further intergenerational damage. The women feel a huge sense of responsibility to assist in restoring the balance and holistic health of First Nations communities and cultures that have been disrupted severely by colonialism and see their agencies as a potential catalyst for meaningful change. The women attempt to build on traditional community strengths to meet the needs of children and families and balance the tension that presents itself as a First Nations person who is working under the dominant mainstream CFS system as a delegated CFS social worker.
The women had feelings of powerlessness and lack of control. The women outlined the challenges, pressures and stresses of working within a family, community and cultural context that affects their holistic health. They also discussed the proximity and intensity of relationships between themselves and their client results in significant stresses on both the personal and professional levels: specifically, the accountability that comes from working with people you know versus people who are anonymous to you increases the stressful nature of the work. This impacts the womens' holistic health in different ways than that experienced by non-First Nations Women CFS Social Workers who don't work within their own tribal cultures, families and communities.

The women also believed that their work can be extremely meaningful and that their strength and power comes from working within First Nations communities and cultures and witnessing the beneficial changes for their community members. They further believe that their continued advocacy toward self-government and determination for First Nations peoples and their creativity and innovation in finding strategies to bridge their community and cultural ways of caring for children is their strength. Overall, the women believe that "to only offer First Nations the opportunity to enforce Euro-Canadian (CFS) law in their communities is not good enough" (Absolon, Mitchell \& Armitage, 1996, p.13).

The women believe that when they are unable to meet the needs of the community members, their holistic health becomes impacted negatively and the large systemic issues of colonization and oppression are the core reasons that block the way forward. "First Nations peoples have to be empowered, financially, politically, and otherwise, to develop their own child welfare services outside of the framework of existing provincial legislative schemes" (Kline, 1992, p. 417).

For the women, this research process is a first step towards creating dialogue about their own individual and collective strategies to "raise critical consciousness" 
and take further "political action" which would assist in benefiting their own holistic health, as well as the health of their First Nations children, families and communities (Brown \& Tandon, 1983, p.283).

\section{Implications for Policy, Practice and Research}

The participatory community action research process and First Nations gendered analysis has been meaningful in engaging with women in a way that gave voice to their experiences. The process made space for individual and collective conversations to happen about the importance of holistic health and coming up with strategies that can assist in restoring and rebalancing the holistic health of the women and First Nations children and families. The women identified the importance of this research and the relationship with the researcher, along with the need for further research of this nature that respects and validates their voices and experiences. On a personal note, this research process was validating for me personally because of my own struggles of working within a dominant mainstream academic social work program and research course. I did not feel fully supported in that particular social work course, especially of having my Aboriginal decolonization approach and process legitimized within its own right. As I young Heiltsuk woman, I received so much validation, support, pride and teachings from the women. Schools of Social Work and other Social Service institutions need to continue to support First Nations students and peoples in their research and academic endeavours.

The Canadian dominant mainstream society and government systems and employees need to recognize, resource and support First Nations CFS research on the local, provincial and national level that validates First Nations peoples realities, voices and builds on their traditional values, systems, knowledge and cultural and community strengths. The dominant mainstream culture and social work profession can learn from First Nations peoples research approaches, as it appears that there is a benefit in doing participatory community action research from a gendered First Nations perspective and decolonization approach. Future research could build on this present study and interview a larger sample of women CFS Social Workers, as well as, explore the systemic, individual and collective strategies for First Nations women CFS Social Workers to restore and rebalance their own holistic health and the health of the community members with whom they work. Other areas for future research include:

+ Compare and contrast First Nations CFS and Non-First Nations CFS settings, models and social workers' experiences;

+ Study existing First Nations CFS programs that are successful within a self-government framework; and

+ Study First Nations and Non-First Nations programs and partnerships that are implementing decolonizing relationships and successful outcomes for First Nations children, families, communities and cultures.

\section{Implications for Social Work Policy}

Many reports such as The 1996 Royal Commission of Aboriginal Peoples Report(s) and The 1992 Liberating Our Children, Liberating Our Nations Report confirm the over-representation of First Nations children in social and health statistics. This raises important questions. For instance: What has changed in the relationship between First Nations peoples and the larger Canadian dominant mainstream society and government systems? Have social work practices progressed to a place where it is responsive and respectful to the needs and strengths of First Nations children and peoples? Why have recommendations in reports such as The 1996 Royal Commission of Aboriginal Peoples Report(s) not been implemented to respond to First Nations peoples' testimonials that the recognition of self-government would assist in restoring the holistic health of their Nations and ensure sustainable futures? What recommendations 
or commitments has the larger society or government followed through on?

The colonial relationship needs to change between First Nations peoples and Canadian dominant mainstream society and government systems. The Canadian government, CFS systems and social workers need to critically and morally reflect on their ideologies, policies, practices and relationships with First Nations peoples and recognize the impacts of their past and current actions. They need to coordinate their efforts to make necessary moral changes in their practices with regard to First Nations peoples. Bruyere (2001) states, "to me the issue is not one of trying to better a bad way of doing things... [past and current CFS practices $\&$ policies]..., but doing things differently... [and being committed to meaningful change]" (p. 312). The current CFS system is not working for First Nations peoples and it is critical that things be done differently or they will continue to negatively impact First Nations peoples on all levels: children, families, communities, cultures and the First Nations social Workers themselves.

The Canadian government needs to acknowledge and fulfill the commitments that have been made to First Nations peoples through such documents as The 1999 Strategic Plan for Aboriginal Services Report, The 1996 Royal Commission of Aboriginal Peoples Report(s), The June 2000 First Nations Child and Family Services Joint Review Final Report, The 1992 Liberating Our Children, Liberating Our Nation Report and other such reports.

Meaningful and respectful consultation needs to happen with First Nations peoples. Policies need to be changed to incorporate a process of accountability and responsibility to building partnership relationships that are based on the sharing of power, adequate and equitable resources and working within the context of selfdetermination and self-governance. Overall, the Canadian government, along with the social service systems must be vigilant about changing their systems, policies, practices and relationship with Aboriginal peoples in a way that is not colonial and paternalistic in nature. The Canadian government and social service organizations need to work with Aboriginal peoples to find innovative ways and meaningful solutions to remedy the injustices towards Aboriginal peoples, in particular children: who are the most impacted and vulnerable.

\section{Implications for Social Work Practice}

Child welfare continues to have huge impact on the lives and cultures of First Nations peoples. The practice of delegating authority to First Nations peoples places them in position of being a perpetrator against their own peoples, and all the while negates their own ways and systems. This is contradictory to the fundamental philosophy and ethics that social work professes to.

How can First Nations social workers maintain their holistic health under the racism, patriarchy and colonialism that they face in their daily lives and work? The systemic issues have to be addressed and the unique challenges that First Nations peoples and social workers face have to be acknowledged and given voice and attention to at all levels. First Nations women CFS Social Workers have the challenge of rebalancing their holistic health on an individual basis and the even bigger challenge of advocating with the mainstream dominant systems for the dream of freedom and selfdetermination of First Nations peoples.

The social work profession needs to be vigilant in their practice and efforts to understand the colonial realities and dreams of First Nations peoples. They need to engage in conversations, processes and relationships with First Nations peoples and take actions that will bring about beneficial change for First Nations peoples. Bruyere (2001) notes that First Nations peoples have dreams... [and that]... "the most crucial aspect of those dreams involves the wellbeing and vitality of Aboriginal children and families." He asks the question of "what would happen if enough Aboriginal and non-Aboriginal peoples experienced and followed the same kinds of dreams 
for Aboriginal children and families in Canada?" He speaks to the importance of vision, immersing ourselves in a shared dream (p. 295). It is time to reconcile and change the nature of relationships between Aboriginal and Non-Aboriginal peoples, especially within child and family services, for this dream to become a reality.

The women's stories speak to their CFS experiences and challenges in endeavouring to carry out that same dream for our Aboriginal children. I will complete the circle of writing this paper by using the words, hopes and dreams of one of the women that echo my own heartfelt sentiment for the present and future generations:

I only hope that when my grandson grows up, I hope that we are not at the place of still thinking about and trying to bring our kids back home to our communities. They should all be home by then (participant).

\section{Michelle Reid}

Michelle Reid, a member of the Heiltsuk Nation, is an Assistant professor in the Thompson Rivers University School of Social Work. Michelle has worked in the areas of child and family services (CFS), health and with people with disabilities. She serves on various community and provincial health, education and CFS committees and boards. Michelle has developed curriculum in the areas of social work and Aboriginal child and family services.

\section{References}

Absolon, K., Mitchell, J., \& Armitage, A. (1996). The Development of the Child and Family Service Act: An Aboriginal Perspective. Victoria, British Columbia: University of Victoria, Child and Family Research Program, School of Social Work.

Absolon, K., \& Willett, E. C. (2004). Putting ourselves forward: Location in Aboriginal research. In L. Brown \& S. Strega (Eds.), Research as resistance: Innovative, critical and anti-oppressive approaches to knowledge creation. Toronto: Canadian Scholars Press.

Anderson, K. (2000). A recognition of being: Reconstructing Native womanhood.

c) Michelle Reid
Toronto, ON: Second Story Press.

Anderson, K., \& Lawrence, B. (Eds). (2003). Strong women stories: Native vision and community survival. Toronto, ON: Sumach Press.

Armitage, A. (1993). Towards First Nations Control of Child Welfare in Canada. In, B. Wharf (Ed.), Rethinking Child Welfare in Canada (pp.172209). Toronto, ON: McClelland \& Stewart

Bennett, M. (2004). First Nations Fact Sheet: A General Profile on First Nations Child Welfare In Canada. Ottawa, ON: First Nations Child $\&$ Family Caring Society of Canada. Available online at: http://www.fncfcs.com/docs/FirstNationsFS1.pdf.

Blackstock, C. \& Bennett, M. (in press). First Nations Child and Family Services and Indigenous Knowledge as a framework for research, policy and practice. In Positive Systems of Child and Family Welfare: International Comparisons, (Vol 2.), G. Cameron, N. Freymond, (Eds). Wilfred Laurier University Press or Sage Publishing. Based on a paper prepared for conference proceedings of positive systems of child welfare, June 2002. Waterloo, ON: Wilfred Laurier University Press.

Blackstock, C. (2003). "First Nations Child and Family Services: Restoring Peace and Harmony in First Nations communities". In B. Mckenzie \& K. Kufeldt (Eds.), Connecting Research, Policy and Practice. Waterloo, ON: Wilfred Laurier University Press.

Blackstock,C. (2004). Aboriginal Child Welfare. In Nicholas Bala, Michael Kim Zapf, R. James Williams, Robin Vogl, \& Joseph P. Hornick. (Eds.)., Canadian child welfare law: Children, families and the state ( $2^{\text {nd }} \mathrm{ed}$.). Toronto: $\mathrm{ON}$ : Thompson Educational Publishing, Inc.

Brown, L., Haddock, L., \& Kovach, M. (2001). Watching Over Our Families: Lalumutul smun'eem Child and Family Services. In B. Wharf (Eds.), Community Work Approaches to Child Welfare (pp.131-151). Peterborough, ON: Broadview Press, LTD.

L. Brown \& S. Strega (Eds.). 2004. Research as resistance: Innovative, critical and antioppressive approaches to knowledge creation. Toronto: Canadian Scholars Press.

Brown, L., \& Tandon, R. (1983). The Ideology and Political Economy of Inquiry: Action Research and Participatory Research. Journal of Applied Behavioral Science and Technology: An International Perspective, 19 (3), 277-94.

Bruyere, G. (2001)."The Lessons in our blood: Reflections on Protecting Aboriginal children", in Hagar International Social Science Review. Vol. 2 (2): 295-315.

Caring for First Nations Children's 
Society Website $w w w . c f n c s . c o m$

Durst, D., Mcdonald, J., \& Rich, C. (1995). "Aboriginal Governance of Child Welfare Services: Hobson's Choice?" In J. Hudson \& B. Galaway (Eds.), Child Welfare in Canada: Research and Policy Implications (pp.41-62). Toronto, ON: Thompson Educational Publishers.

Durst, D. (1996). First Nations self-government: An annotated bibliography. Regina, Saskatchewan: University of Regina, School of Social Work Administration Research Unit.

Gilchrist, L. (1997). Aboriginal communities and social science research: Voyeurism in transition. Native Social Work Journal, 1(1), pp. 69-85.

Glaser, B., \& Strauss, A. (1967). The Discovery of Grounded Theory: Strategies for Qualitative Research. New York: Aldine Publishing Co.

Gold, Nora. (1998). Using Participatory Research to Help Promote the Physical and Mental Health of Female Social Workers in Child Welfare. Child Welfare, 77, 701-724.

Gunn Allen, P. The sacred hoop: Recovering the feminine in American Indian tradition Boston, Massachusetts: Beacon Press Books.

Hampton, E. (1995). Memory comes before knowledge: Research may improve if researchers remember their motives. Canadian Journal of Native Education, 21, pp. 46-54.

Hamilton, A.C., \& Sinclair, C.M. (1991). Report of the Aboriginal Justice Inquiry of Manitoba. "Child Welfare” Chapter 14. Winnipeg, Manitoba.

Howse, Y.,Stalwick, H. (1990). Social Work and the First Nations Movement: Our Children, Our Culture. In B. Wharf (Ed.), Social Work and Social Change in Canada (pp.79-113). Toronto: McClelland and Stewart.

Johnson, P. (1983). Native Children and the Child Welfare System. Toronto, ON: James Lorimer \& Company in association with the Canadian Council on Social Development.

Kline, M. (1992). Child Welfare Law,"Best Interests of Child" Ideology, and First Nations, Osgoode Hall Law Journal, 30, No. 2, 375-425.

Kirby, S. and K. McKenna. 1989. Experience, Research, Social Change: Methods from the Margins. Toronto: Garamond Press.

K.J. Lee \& Associates LTD (1992). Liberating Our Children, Liberating Our Nations. Report of Aboriginal Committee-Community Panel, Family and Children's Service, Legislation Review in British Columbia.

Kovach, M. (2004). Emerging from the Margins:
Indigenous Methodologies. In L. Brown \& S. Strega (Eds.), Research as resistance: Innovative, critical and anti-oppressive approaches to knowledge creation. Toronto: Canadian Scholars Press.

Lawrence, B. (2004). "Real" Indians and Others: Mixed blood urban Native peoples and Indigenous nationhood. Vancouver, BC: UBC Press.

MacDonald, K. (2000). First Nation Summit Action Committee for First Nations Children and Families Discussion Paper. Vancouver: First Nations Summit

MacDonald, K (2002). Missing Voices: Aboriginal Mothers Who Have Been at Risk of or Who Had Their Children Removed From Their Care Phase 2 Report. Vancouver: NAC-BC Region \& Legal Service Society: Native Programs Dept.

McDonald, R.J. \& Ladd et al. June 2000. First Nations Child and Family Services Joint National Policy Review. Final Report prepared for the Assembly of First Nations (AFN) with First Nations Child and Family Service Agency Representatives in partnership with the Department of Indian Affairs and Northern Development (DIAND). Ottawa: AFN \& DIAND.

Mckenzie, B., \& Hudson, P. (1981). Native Children, Child Welfare, and The colonization of Native People. In K.L. Levitt \& B. Wharf (Eds.), The Challenge of Child Welfare (pp. 121-141). Vancouver, BC: University of British Columbia Press.

Mckenzie, B., Seidl, E., \& Bone, N. (1995). Child Welfare Standards in First Nations: An Action Research Project. Child Welfare: Journal of Policy, Practice and Program, 3, 633-652.

Maracle, L. (1996). I am woman: A Native perspective on sociology and feminism. Vancouver, BC: Press Gang Publishers.

Martin, K. 2001. Ways of Knowing, Ways of Being and Ways of Doing: Developing a Theoretical Framework and Methods for Indigenous ReSearch and Indigenist Research. Available online at www.aiatsis.gov.au/rsrch/conf2001.

Mihesuah, D.A., (Ed.), Natives and academics: Researching and writing about American Indians. Lincoln Nebraska: University of Nebraska Press.

Mihesuah, D.A. (2003). Indigenous American women: Decolonization, empowerment, activism. Licohn Nebraska: University of Nebraska Press.

Ministry for Children and Families, The 1999 Strategic Plan for Aboriginal Services (SPAS). Victoria, BC: Queens Printer.

Monture-Angus. P. (1995). Thunder in my soul: A Mobawk woman speaks. Halifax, NS: Fernwood Publishing.

"North Short of Help for Native Children." (May 28, 2001). The Globe and Mail.

Ouellette, J.M.W. (2002). The fourth world: An 
Indigenous perspective on feminism and Aboriginal women's activism. Halifax, NS: Fernwood Publishing.

Report on the Standing Committee on Health. (1995). Towards Holistic Wellness: The Aboriginal Peoples. Canada Communications group, Public Works and Government Services, Ottawa, Canada.

Royal Commission on Aboriginal Peoples, Gathering Strength, Vol. 3. (Ottawa: Supply and Services, 1996).

Royal Commission on Aboriginal Peoples, Realities and Perspectives, Vol. 4. (Ottawa: Supply and Services, 1996).

Sayers, J., \& Macdonald, K (2001). A Strong and Meaningful Role for First Nations Women in Governance. In First Nations Women, Governance and the Indian Act: A Collection of Policy Research Reports. (pp. 1-54). Ottawa, ON: Status of Women Canada.

Smith, T, L. (1999). Decolonizing Methodologies: Research and Indigenous Peoples. Dunedin, New Zealand: University of Otago Press.

Stewart, W., Huntley, A., \& Blaney, F. (2001). “The Implications of Restorative Justice For Aboriginal Women and Children Survivors of Violence: $A$ Comparative Overview of Five Communities in British Columbia". Vancouver: A Project of the Aboriginal Women's Action Network (AWAN).

Thomas, R. (2004). Honouring the oral traditions of my ancestor through storytelling. In L. Brown \& S. Strega (Eds.), Research as resistance: Innovative, critical and anti-oppressive approaches to knowledge creation. Toronto: Canadian Scholars Press.

Timpson, J. (1995). Four Decades of Literature on Native Canadian Child Welfare: Changing Themes. Child Welfare, 3, 525-546.

Wotherspoon, T., \& Satezwich, V. (1993). First Nations: Race, Class, and Gender Relations. Chapter 7, Scarborough: Nelson Canada Publishers, pp. 147-179.

Wuest, J. (1995). Feminist Grounded Theory. QHR 5/1: 125-137 